\title{
Primary headache disorders
}

\section{Five new things}

Peter J. Goadsby

Neurology: Clinical Practice June 2019 vol. 9 no. 3 233-240 doi:10.1212/CPJ.0000000000000654

Correspondence

Dr. Goadsby

peter.goadsby@kcl.ac.uk

\section{Abstract \\ Purpose of review}

To review 5 new areas in primary headache disorders, especially migraine and cluster headache.

\section{Recent findings}

Calcitonin gene-related peptide (CGRP) receptor antagonists (gepants-rimegepant and ubrogepant) and serotonin 5- $\mathrm{HT}_{1 \mathrm{~F}}$ receptor agonists (ditans-lasmiditan) have completed phase 3 clinical trials and will soon offer novel, effective, well-tolerated nonvasoconstrictor options to treat acute migraine. CGRP preventive treatment is being revolutionized after the licensing of 3 monoclonal antibodies (MABs), erenumab, fremanezumab, and galcanezumab, with eptinezumab to follow, especially designed for migraine; they are effective and well tolerated. For patients seeking a nondrug therapy, neuromodulation approaches, single-pulse transcranial magnetic stimulation, noninvasive vagus nerve stimulation (nVNS), and external trigeminal nerve stimulation, represent licensed, well-tolerated approaches

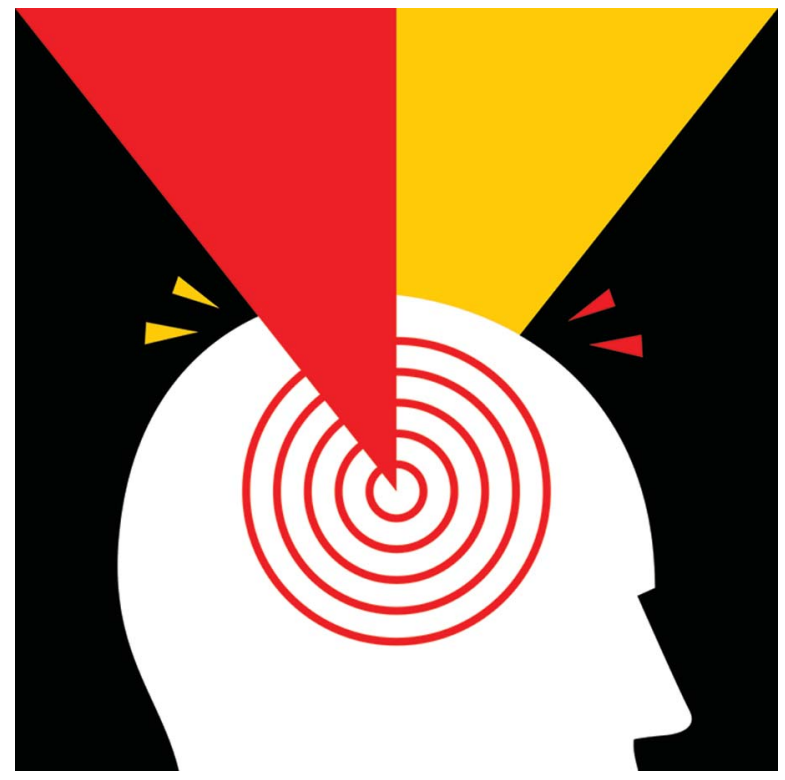
to migraine treatment. For the acute treatment of episodic cluster headache, nVNS is effective, well tolerated, and licensed; nVNS is effective and well tolerated in preventive treatment of cluster headache. The CGRP MAB galcanezumab was effective and well tolerated in a placebo-controlled trial in the preventive treatment of episodic cluster headache. Sphenopalatine ganglion stimulation has been shown to be effective and well tolerated in 2 randomized sham-controlled studies on chronic cluster headache. Understanding the premonitory (prodromal) phase of migraine during which patients experience symptoms such as yawning, tiredness, cognitive dysfunction, and food cravings may help explain apparent migraine triggers in some patients, thus offering better self-management.

\section{Summary}

Headache medicine has made remarkable strides, particularly in understanding migraine and cluster headache in the past 5 years. For the most common reason to visit a neurologist, therapeutic advances offer patients reduced disability and neurologists a rewarding, key role in improving the lives of those with migraine and cluster headache.

Primary headache disorders, such as migraine and cluster headache, are the most common reasons, for which patients seek neurologic advice, and every year affect nearly 3 billion people ${ }^{1}$; thus, any new therapy would be of broad interest. It was a challenge to adopt a marmoreal attitude to a single therapeutic advance, triptans, serotonin $5-\mathrm{HT}_{1 \mathrm{~B} / 1 \mathrm{D}}$ receptor agonists, when they came. ${ }^{2}$ Thirty years later, and certainly since the last of this series of 
Preventive therapy targeting the CGRP pathway using monoclonal antibodies or small molecule CGRP receptor antagonists offer

\section{a remarkable clinical advance.}

articles in 2011, 4 new things have happened in therapeutics alone; exciting seems a trite description when thinking about headache medicine in 2019. Because new treatments are affecting, or will affect, neurologists in 2019, I will cover them in detail. An emerging area of clinical neuroscience is the study of nonheadache phases of migraine, notably the premonitory (prodromal) and postdromal phases. They provide insights into mechanisms that can be used in clinical practice. Many other areas in the primary headache disorders have advanced in the past decade, so readers interested in pathophysiology of migraine ${ }^{3}$ or cluster headache, ${ }^{4}$ headache classification, ${ }^{5}$ or the genetics of headache ${ }^{6}$ are referred to recent reviews wherein wallahs riff.

New acute therapies for migraine attacks, gepants, calcitonin gene-related peptide (CGRP) receptor antagonists, and ditans, serotonin $5-\mathrm{HT}_{1 \mathrm{~F}}$ receptor agonists, offer novel approaches to the treatment. Preventive therapy targeting the CGRP pathway using monoclonal antibodies (MABs) or small molecule CGRP receptor antagonists offers a remarkable clinical advance. Neuromodulation approaches to migraine, both acute and preventive, provide nondrug options for physicians to deploy and patients to take benefit from. Being important for patients and neurologists, therapeutic developments in medicines and neuromodulation are underway for cluster headache. The therapeutic developments are framed as comments from a patient, and replies that clinicians may now make. Citations for data concerning these developments are given in table. Reformulation of triptans is covered here; certainly, more efficient delivery systems, such as a permeation enhancer for nasal sumatriptan ${ }^{7}$ or an adhesive dermally applied microarray for zolmitriptan, ${ }^{8}$ offer new avenues for medicines that are widely used and well liked. Here, newer approaches that neurologists may be less familiar with have been chosen for a more detailed study. Understanding the premonitory phase of migraine affords the clinician expanded dimensions in the clinical history that aid diagnosis and offer an opportunity to demonstrate to patients a deeper understanding of their presentation and disability.

\section{What can you give me for my migraine? I cannot take triptans. Gepants or Ditans?}

Triptans were developed based on the hypothesis that the pain of migraine was due to dilation of extracerebral cranial vessels. ${ }^{9}$ Although undoubtedly useful and effective in suitable patients, triptans have 3 major limitations: not all patients respond, not all patients tolerate the medicines, ${ }^{2}$ and for some patients with cardiovascular or cerebrovascular disease they are contraindicated. ${ }^{10}$ Although the neural, nonvasoconstrictor effect of triptans has been postulated for 2 decades, ${ }^{11}$ the vasodilator hypothesis of migraine took some time to be shown as inadequate. ${ }^{12}$ Readers should not consider that just anything works for migraine; there is a long list of failed approaches, including substance $\mathrm{P} /$ neurokinin 1 receptor antagonists, plasma protein extravasation inhibitors, and TRPV1 receptor antagonists, ${ }^{13}$ which offer comfort to the positive outcomes.

\section{Gepants-CGRP receptor antagonists}

CGRP was shown to be important for migraine in translational studies in the late 1980s. ${ }^{14-16}$ CGRP can trigger migraine, ${ }^{17}$ and blockade of the canonical CGRP receptor ${ }^{18}$ is effective in the treatment of acute migraine (table). Gepants have no active vasoconstrictor effect. Six gepants have been tested, and each was effective in the acute treatment of migraine. Two were terminated during development because of hepatic concerns, which now seem firmly based on metabolites not on the CGRP mechanism. Two CGRP receptor antagonists, rimegepant and ubrogepant, have completed phase III studies. They are both effective at the primary endpoints of being free of pain for 2 hours and most bothersome symptom (MBS), as currently recommended by the US FDA. The latter endpoint is new: patients are asked to nominate which of nausea, photophobia, or phonophobia bothers them the most during the migraine and which symptom is absent for 2 hours. Interestingly, photophobia has dominated in all phase III studies as the MBS. Gepants are remarkably well tolerated with only a few percentage points or less excess of nausea or somnolence reported above placebo. There have been no cardiovascular or cerebrovascular concerns, as would be expected from the mechanism, given peptide redundancy in the CGRP class, nor have liver enzyme issues emerged.

\section{Are gepants potentially disruptive therapies?}

Across the studies, there is remarkable consistency in the population effect: about $20 \%$ of migraineurs are pain free at 2 hours. The population effect is smaller than triptans, or ditans, where about one-third of migraineurs are pain free at 2 hours. From an intrapatient perspective, in pain-free patients, they are just as pain free as they would be on a triptan or a ditan; they may be better off given the tolerability is improved. Moreover, given the preventive data with the CGRP pathway, both from MABs and gepants used preventively, it seems highly likely that medication overuse will simply not be a problem since it would seem the more often a gepant is dosed, the less migraine the patient has. Studies on gepants suggest that the dichotomous view of acute therapies vs preventive therapies for migraine is artificial because the CGRP pathway can be engaged for either purpose. Perhaps the most disruptive aspect of this new class is that biologydriven developments can be targeted at the clinical need not constrained as either acute or preventive. 
Table Licensed or phase III completed treatments

Mechanism/indication

Treatment

Stage

Migraine

CGRP mechanism antagonist

Acute attack treatment

CGRP receptor antagonist (gepant)

Olcegepant $^{35} \quad$ Phase II

Telcagepant-acute ${ }^{36-38} \quad$ Phase $\|/\|^{\|^{a, b}}$

Rimegepant ${ }^{39}$

Phase II

Rimegepant study 301/302 $40 \quad$ Phase III

BI44370TA ${ }^{41}$

Phase $\|^{a}$

MK- $3207^{42}$

Phase $\|^{a, b}$

Ubrogepant $^{43}$

Phase II

Ubrogepant (ACHIEVE-I) ${ }^{44}$

Phase III

Ubrogepant (ACHIEVE-II)

Phase III

\section{Preventive attack treatment}

CGRP antibody ${ }^{\mathrm{a}}$

Episodic migraine

Placebo contro

Osteoarthritis

Eptinezumab $^{46}$

Phase III

Galcanezumab ${ }^{47-50}$

Licensed

Galcanezumab $^{5}$

Fremanezumab ${ }^{52,53}$

Licensed

Chronic migraine

Fremanezumab ${ }^{54,55}$

Licensed

Galcanezumab ${ }^{56}$

Licensed

Eptinezumab $^{57}$

Phase II

CGRP receptor antibody ${ }^{a}$

Episodic migraine

Placebo-controlled studies

Erenumab ${ }^{58-60}$

Licensed

Open-label extension

Erenumab $^{61}$

Efficacy in patients who have

failed 2-4 previous

Erenumab $^{62}$

preventives

Chronic migraine

CGRP receptor antagonist ${ }^{\mathrm{a}}$

Erenumab $^{63}$

Licensed

Telcagepant-preventive ${ }^{64}$

Phase II ${ }^{\mathrm{a}, \mathrm{b}}$

Atogepant ${ }^{65}$

Phase II

Serotonin-related

Serotonin $5-\mathrm{HT}_{1 \mathrm{~F}}$ receptor agonist (ditan)

Lasmiditan $^{66,67}$

Phase II

SAMURAI ${ }^{68}$

Phase II

SPARTAN ${ }^{69}$

Phase II

\section{Neuromodulation strategies}

Acute treatment

sTMS $^{a}$

STMS-eNeura ${ }^{70}$

Licensed 
Table Licensed or phase III completed treatments (continued)

\begin{tabular}{|c|c|c|}
\hline Mechanism/indication & Treatment & Stage \\
\hline \multicolumn{3}{|l|}{ Preventive treatment } \\
\hline sTMS $^{a}$ & references 71 and 72 & Licensed \\
\hline ONS $^{\mathrm{a}}$ & Chronic migraine ${ }^{73-75}$ & Phase II (F) \\
\hline \multicolumn{3}{|l|}{$n V N S^{a}$} \\
\hline Acute treatment & gammaCore device $^{76}$ & Licensed \\
\hline Preventive treatment & gammaCore device ${ }^{77}$ & Phase II (F) \\
\hline \multicolumn{3}{|l|}{ eTNS ${ }^{a}$} \\
\hline Acute therapy & Cefaly $^{78}$ & Licensed \\
\hline Preventive therapy & Cefaly ${ }^{79}$ & Licensed \\
\hline \multicolumn{3}{|l|}{ Cluster headache } \\
\hline \multicolumn{3}{|l|}{ Episodic cluster headache } \\
\hline Acute treatment ${ }^{a}$ & gammaCore-nVNS ${ }^{80,81}$ & Licensed \\
\hline \multirow[t]{2}{*}{ Preventive treatment $^{a}$} & $n V N S^{82}$ & Licensed \\
\hline & Galcanezumab ${ }^{83}$ & Phase III \\
\hline \multicolumn{3}{|l|}{ Chronic cluster headache } \\
\hline \multirow[t]{5}{*}{ Preventive treatment $^{a}$} & $\mathrm{nVNS}^{82}$ & Licensed \\
\hline & SPG stimulation-Pulsante ATI device ${ }^{84,85}$ & Phase III \\
\hline & \multicolumn{2}{|l|}{ SPG stimulation-long term ${ }^{86,87}$} \\
\hline & ONS $^{88}$ & Phase III in progress \\
\hline & Deep brain stimulation ${ }^{89}$ & Study failed \\
\hline Paroxysmal hemicrania & $\mathrm{nVNS}^{90}$ & Open-label report \\
\hline $\begin{array}{l}\text { Abbreviations: CGRP = calcitonin } \\
\text { occipital nerve stimulation; SPG }= \\
\text { a Clinical development stopped fo } \\
\text { b Liver toxicity; F-Failed study pro }\end{array}$ & $\begin{array}{l}\text { rnal trigeminal nerve stimulator; nVNS = nor } \\
\text { single-pulse transcranial magnetic stimulati } \\
\text { reasons. }\end{array}$ & stimulation; ONS = \\
\hline
\end{tabular}

\section{Ditans-serotonin 5- $\mathrm{HT}_{1 \mathrm{~F}}$ receptor agonists}

Not all triptans were created pharmacologically similar; although sumatriptan is active at the $5-\mathrm{HT}_{1 \mathrm{~F}}$ receptor, rizatriptan is not. ${ }^{19}$ Does activation of the $5-\mathrm{HT}_{1 \mathrm{~F}}$ receptor can inhibit trigeminal neuronal activity without any vascular effect? The fact is that there are now 4 positive randomized placebo-controlled trials including 1 with intravenous administration and no cardiovascular adverse events, establishes that a purely neural antimigraine effect works. About one-third of patients in the phase III studies are pain free at 2 hours, and the MBS endpoint was met (table). Dizziness was reported in $16 \%$ and $13 \%$ of patients on 200 and $100 \mathrm{mg}$, respectively, and in $3 \%$ in the placebo arm (SAMURAI; table). It is clear that this medicine acts centrally in some parts. There will be a clinical balance to strike; vertigo is a very common sensation in migraine. It is not yet clear from the studies whether dizziness was a price to pay for headache resolution or unrelated; in general, no side effect of triptans seems to predict efficacy reliably, if that is any guide. For patients who have failed to respond or have contraindications to triptans, ditans will probably be available. Unsurprisingly, given their presynaptic action in contrast to the postjunctional/synaptic action of gepants, more patients respond. Perhaps also not surprising is an emerging broad principle that more specific treatments in terms of targets yield generally fewer side effects. Presynaptic approaches block the release of multiple transmitters, so they are generally more likely to work across a population and more likely to have some side effects, whereas postsynaptic, single transmitter targets broadly treat a smaller population and seem generally better tolerated. Both will be welcome additions to our therapeutic options in the future.

\section{I have too many migraines: I will give you a migraine preventive}

About $40 \%$ of patients with episodic migraine, ${ }^{20}$ i.e., affected less than 15 days a month, and probably all patients with 
chronic migraine should be offered preventive therapy. If one considers compliance as an indication, $80 \%$ or more of patients with chronic migraine will be nonadherent to treatment at 12 months. ${ }^{21}$ Some part of this must be clinical improvement, certainly not all. Current migraine preventive therapies provide an eclectic mechanistic background: hypertension, epilepsy, depression, neurotoxin or neutriceutical supplements. Each dragooned into migraine without a theme or particular insight into the underlying condition. How often has the reader said in response to the patient comment above: I will give you $\mathrm{X}$ - it was developed for Y but works in migraine-don't worry.... CGRP pathway blockers provide the first mechanism-specific, migrainebespoke preventive therapies for the condition. Three MABs are now licensed: 2 to the peptide (galcanezumab and fremanezumab), with 1 to come (eptinezumab), and 1 to the canonical CGRP receptor (erenumab). I emphasize canonical here, the calcitonin receptor (CTR)-like receptor/ receptor activity modifying peptide 1 (RAMP-1), CGRP receptor, as opposed to the amylin, CTR/RAMP-1, receptor that ex vivo can be activated by CGRP. ${ }^{22}$ This will hopefully be resolved soon in vivo. The MABs are effective in episodic migraine from 4 to 14 days and chronic migraine (table). They are extremely well tolerated with dropout rates a few percent compared with, for example, the topiramate development program at $30 \%$ or more. Injection site discomfort is the common side effect in the class, and constipation has emerged greater than the softer numbers in the controlled trials. There have been no cardiovascular issues, no liver enzyme issues, and predictably, as MABs, no drug interactions. Of the responders who continue on therapy for a year, a remarkable $40 \%$ will have a $75 \%$ or more reduction in migraine days, while approximately $25 \%$ will be migraine free (table). Moreover, retrospective and prospective studies demonstrate that patients who have failed up to 4 previous preventives are still likely to respond to these medicines; this is naturally the group clinicians will be treating early in their experience (table). Safety in medium-term use, up to 3 years, is reassuring; notably a study of galcanezumab on osteoarthritis was negative in terms of efficacy, no new adverse events appeared in this somewhat older cohort (table). Not all patients respond because it is likely that CGRP is at least not so important in all patients and perhaps even varies in pathophysiologic significance within patients over time. It is obvious, even jejune, to say we do not know what we cannot know: what will happen in the long term for both efficacy and side effects. No doubt-despite redundancy, CGRP is important in some individuals in ways that we are yet to understand. As we know that large numbers of migraineurs have now been exposed to, many have performed very well for the short term and few have had tolerability problems associated with current therapies. How the MABs will be positioned in chronic migraine therapy with regard to onabotulinum toxin type A will take time to resolve. Given the large unmet need in migraine prevention, it is easy to see the treated pool increase, and the need for neurologic expertise expanded, with growth in all the tools we have.

\section{I do not want another pill for my migraine: I have nompill options}

This refrain will be familiar to every practicing neurologist; it is borne of genuine and reasonable frustration with pharmacologic therapies that have not worked or resulted in a plethora of side effects. Devices with near-zero morbidity, and approved by the US Food and Drug Administration (FDA), can now be deployed for both acute and preventive treatment of migraine. Single-pulse transcranial magnetic stimulation (sTMS) delivers a nominal $0.9 \mathrm{~T}$ pulse over cranial bone that has been shown in experimental settings to alter dural nociceptive trigeminothalamic activation. ${ }^{23}$ This device is approved by the FDA for both acute and preventive treatments of migraine (table). Given the established safety of MRI during pregnancy, ${ }^{24}$ it can be extremely useful in clinical practice as well. Noninvasive vagus nerve stimulation (nVNS) delivers five $5 \mathrm{kHz}$ pulses at $25 \mathrm{~Hz}$ for 120 seconds; it has been shown to alter nociceptive trigeminovascular transmission in experimental settings. ${ }^{25}$ The device is FDA approved for acute treatment of migraine and well tolerated in practice (table). Stimulation of the supraorbital region with an external trigeminal nerve stimulator (eTNS) is FDA approved for both acute and preventive treatments of migraine (table). The device delivers a $100-\mathrm{Hz}$ stimulation to the forehead bilaterally with a cutaneous adhesive device, which in preventive use alters brain activity in the orbitofrontal and rostral anterior cingulate cortices. ${ }^{26}$ Finally, it should be noted that there are 3 negative studies for occipital nerve stimulation (ONS) in migraine (table). It can be argued, based on the data, that ONS should only be considered after noninvasive neuromodulation, at least 3 standard oral preventives of different classes, a CGRP peptide and a receptor $\mathrm{MAB}$, and a course of intravenous dihydroergotamine in the hospital, ${ }^{27}$ including any medication overuse withdrawal (not listed here in a particular order).

\section{Please help me; I have cluster headache: Yes, I can do that}

This is a simple refrain of deep suffering that demands our attention. Clinicians will immediately understand why therapeutic advances are important here. Current standard of care for the acute treatment of cluster headache includes inhaled oxygen, intranasal zolmitriptan or sumatriptan, and injectable sumatriptan. ${ }^{4} \mathrm{nVNS}$ has now 2 positive shamcontrolled studies (table) and is FDA approved for the acute treatment of attacks in episodic cluster headache; the device was not effective in chronic cluster headache. The device is also approved for the preventive treatment of both episodic and chronic cluster headache. Although not FDA approved, nVNS has been reported to be effective in paroxysmal hemicrania and hemicrania continua-indomethacinsensitive trigeminal autonomic cephalalgias that can be very difficult to manage when patients develop GI 
Being aware of premonitory

symptoms then becomes

\section{a management strategy for patients that affords them some degree of predictability.}

complications of indomethacin (table). Based on good translational studies showing CGRP is elevated in acute cluster headache ${ }^{28}$ and CGRP can trigger attacks in patients in bout, ${ }^{29}$ galcanezumab, a CGRP MAB, has been shown in a randomized placebo-controlled trial to be effective in the preventive management of episodic cluster headache. Again, it is of interest that no effect was seen in chronic cluster headache (table). For clinicians who manage patients with chronic cluster headache, 2 studies have recently reported the efficacy of sphenopalatine ganglion (SPG) stimulation with the Pulsante device against shamcontrolled devices (table). SPG stimulation is effective in both treating acute attacks and reducing the frequency of attacks in the long term (table). The device is well-tolerated and, importantly, was designed for the purpose. ONS is currently being evaluated for cluster headache in a controlled trial (table) and thus should be viewed as experimental. Deep brain stimulation has been shown in a sham-controlled trial to be ineffective (table); its use, if any, should be in experimental settings only as a last resort.

\section{Should I avoid chocolate to prevent my migraine: No!}

One can hear a groan as the reader recalls the very many times this and questions like these being asked - the apparent holy grail of trigger avoidance. The premonitory (prodromal) phase of migraine consists of a period of hours or days before the headache phase in which symptoms, such as tiredness, yawning, neck discomfort, mood change, cognitive impairment (a brain fog), thirst, polyuria, or cravings for sweet or salty foods, begin. ${ }^{5}$ Observation and clinical history taking will also show that cranial autonomic symptoms, such as lacrimation, nasal congestion, or aural fullness, ${ }^{30}$ can occur, as can nausea, photophobia, or phonophobia. Indeed, these symptoms can all persist in the headache phase. The premonitory phase is marked by functional imaging changes in the region of the hypothalamus. ${ }^{31,32}$ Given the known roles and interactions between satiety mechanisms, nociception, and the hypothalamus, ${ }^{3,33}$ one might reformulate the trigger search question. Perhaps, for example, in some patients, they have a hypothalamic-driven consumption of sweet foods 6-8 hours before a migraine; they succumb to the desire, and they suffer a migraine. They make the completely correct association of migraine with chocolate consumption for a completely wrong reason because their attack has already started. Similarly, light sensitivity does not trigger migraine but warns of its onset. Being aware of premonitory symptoms then becomes a management strategy for patients that affords them some degree of predictability. The neurologic history begins to both build confidence in the therapeutic relationship and, through pathophysiologic knowledge, the neurologist is adding a clinical value to the migraineur.

\section{Conclusion}

Although primary headache disorders have their challenges, such as the epistemological limits of self-reference in the current system of headache classification ${ }^{5}$ that only biology will resolve, the lack of new treatments for tension headache, or the inadequate funding by NINDS and other agencies to headache medicine over the past 30 years, neurologists for reasons of interest or utility can embrace new therapeutics. Being able to offer a migraine patient a migraine bespoke preventive, rather than a hand-me-down from another condition, demonstrates an apophthegm that biological research works. Deploying the new acute and preventive therapies or neuromodulation approaches, and indeed explaining advances in pathophysiology, such as understanding the premonitory phase to shed light on putative migraine triggers, ${ }^{34}$ underscores the value of neurology to patients and broadly to society. This is an exciting time to be in medicine and the most exciting period to be in headache medicine.

\section{Author contributions}

Drafting/revising the manuscript, data acquisition, and analysis or interpretation of data.

\section{Study funding}

No targeted funding reported.

\section{Disclosure}

P.J. Goadsby reports personal fees from Alder Biopharmaceuticals, personal fees from Allergan, grants and personal fees from Amgen, personal fees from Autonomic Technologies Inc, grants and personal fees from Eli Lilly and Company, personal fees from Electrocore LLC, personal fees from eNeura Inc, personal fees from Impel NeuroPharma, personal fees from MundiPharma, personal fees from Novartis, personal fees from Dr Reddy's Laboratories, personal fees from Teva Pharmaceuticals, other fees from Trigemina, personal fees from Biohaven Pharmaceuticals Inc, personal fees from Oxford University Press, personal fees from Massachusetts Medical Society, personal fees from Wolters Kluwer, and personal fees from MedicoLegal work, outside the submitted work. In addition, P.J. Goadsby has a patent magnetic stimulation for headache licensed to eNeura without fee. Full disclosure form information provided by the author is available with the full text of this article at Neurology.org/cp. 
FIVE NEW THINGS

1. CGRP receptor antagonists, gepants (rimegepant and ubrogepant), and serotonin $5-\mathrm{HT}_{1 \mathrm{~F}}$ receptor agonists, ditans (lasmiditan), have completed phase 3 clinical trials and will soon offer novel, effective, well-tolerated nonvasoconstrictor options to treat acute migraine.

2. CGRP preventive treatment is being revolutionized after the licensing of 3 MABs, erenumab, fremanezumab, and galcanezumab, especially designed for migraine that are effective and well tolerated.

3. For patients seeking a nondrug therapy, neuromodulation approaches, sTMS, nVNS, and eTNS, represent licensed, well-tolerated approaches to migraine treatment.

4. For the acute treatment of episodic cluster headache, nVNS is effective, well tolerated, and licensed; nVNS is effective and well tolerated in preventive treatment of cluster headache. The CGRP MAB galcanezumab was effective and well tolerated in a placebo-controlled trial in the preventive treatment of episodic cluster headache. SPG stimulation has been shown to be effective and well tolerated in 2 randomized sham-controlled studies in chronic cluster headache.

5. Understanding the premonitory (prodromal) phase of migraine during which patients experience symptoms such as yawning, tiredness, cognitive dysfunction, and food cravings may help explain apparent migraine triggers in some patients, thus offering better self-management.

\section{Publication history}

Received by Neurology: Clinical Practice January 3, 2019. Accepted in final form April 17, 2019.

\section{References}

1. Collaborators GBDH. Global, regional, and national burden of migraine and tensiontype headache, 1990-2016: a systematic analysis for the Global Burden of Disease Study 2016. Lancet Neurol 2018;17:954-976.

2. Goadsby PJ, Lipton RB, Ferrari MD. Migraine: current understanding and treatment. N Engl J Med 2002;346:257-270.

3. Goadsby PJ, Holland PR, Martins-Oliveira M, Hoffmann J, Schankin C, Akerman S. Pathophysiology of migraine-A disorder of sensory processing. Physiol Rev 2017;97:553-622.

4. Hoffmann J, May A. Diagnosis, pathophysiology, and management of cluster headache. Lancet Neurol 2018;17:75-83.

5. Headache Classification Committee of the International Headache Society (IHS). The International classification of headache disorders, 3rd edition. Cepahalalgia 2018;38:1-211.

6. Tolner EA, Houben T, Terwindt GM, de Vries B, Ferrari MD, van den Maagdenberg AM. From migraine genes to mechanisms. Pain 2015;156(suppl 1):S64-S74.

7. Lipton RB, Munjal S, Brand-Schieber E, Rapoport AM. DFN-02 (sumatriptan $10 \mathrm{mg}$ with a permeation enhancer) nasal spray vs placebo in the acute treatment of migraine: a double-blind, placebo-controlled study. Headache 2018;58:676-687.
8. Spierings EL, Brandes JL, Kudrow DB, et al. Randomized, double-blind, placebocontrolled, parallel-group, multi-center study of the safety and efficacy of ADAM zolmitriptan for the acute treatment of migraine. Cephalalgia 2018;38:215-224.

9. Humphrey PP, Feniuk W, Perren MJ, Beresford IJ, Skingle M, Whalley ET. Serotonin and migraine. Ann N Y Acad Sci 1990;600:587-600.

10. Dodick D, Lipton RB, Martin V, et al. Consensus statement: cardiovascular safety profile of triptans $\left(5-\mathrm{HT}_{1 \mathrm{~B} / 1 \mathrm{D}}\right.$ agonists) in the acute treatment of migraine. Headache 2004;44:414-425.

11. Goadsby PJ, Hoskin KL. Inhibition of trigeminal neurons by intravenous administration of the serotonin $(5 \mathrm{HT})_{1 \mathrm{~B} / \mathrm{D}}$ receptor agonist zolmitriptan (311C90): are brain stem sites a therapeutic target in migraine? Pain 1996;67:355-359.

12. Charles A. Vasodilation out of the picture as a cause of migraine headache. Lancet Neurol 2013;12:419-420.

13. Goadsby PJ. Bench to bedside advances in the 21 st century for primary headache disorders: migraine treatments for migraine patients. Brain 2016;139:2571-2577.

14. Goadsby PJ, Edvinsson L, Ekman R. Release of vasoactive peptides in the extrac erebral circulation of man and the cat during activation of the trigeminovascular system. Ann Neurol 1988;23:193-196.

15. Goadsby PJ, Edvinsson L, Ekman R. Vasoactive peptide release in the extracerebral circulation of humans during migraine headache. Ann Neurol 1990;28:183-187.

16. Goadsby PJ, Edvinsson L. The trigeminovascular system and migraine: studies characterizing cerebrovascular and neuropeptide changes seen in humans and cats. Ann Neurol 1993;33:48-56.

17. Lassen LH, Haderslev PA, Jacobsen VB, Iversen HK, Sperling B, Olesen J. CGRP may play a causative role in migraine. Cephalalgia 2002;22:54-61.

18. Russell FA, King R, Smillie SJ, Kodji X, Brain SD. Calcitonin gene-related peptide physiology and pathophysiology. Physiol Rev 2014;94:1099-1142.

19. Rubio-Beltran E, Labastida-Ramirez A, Villalon CM, MaassenVanDenBrink A. Is selective 5-HT1F receptor agonism an entity apart from that of the triptans in antimigraine therapy? Pharmacol Ther 2018;186:88-97.

20. Lipton RB, Bigal ME, Diamond M, Freitag F, Reed ML, Stewart WF. Migraine prevalence, disease burden, and the need for preventive therapy. Neurology 2007;68:343-349.

21. Hepp Z, Dodick DW, Varon SF, Gillard P, Hansen RN, Devine EB. Adherence to oral migraine-preventive medications among patients with chronic migraine. Cephalalgia 2015;35:478-488

22. Walker CS, Eftekhari S, Bower RL, et al. A second trigeminal CGRP receptor: function and expression of the AMY1 receptor. Ann Clin Transl Neurol 2015;2: $595-608$

23. Andreou AP, Holland PR, Akerman S, Summ O, Fredrick J, Goadsby PJ. Transcranial magnetic stimulation and potential cortical and trigeminothalamic mechanisms in migraine. Brain 2016;139:2002-2014.

24. Ray JG, Vermeulen MJ, Bharatha A, Montanera WJ, Park AL. Association between MRI exposure during pregnancy and fetal and childhood outcomes. JAMA 2016;316: 952-961.

25. Akerman S, Simon B, Romero-Reyes M. Vagus nerve stimulation suppresses acute noxious activation of trigeminocervical neurons in animal models of primary headache. Neurobiol Dis 2017;102:96-104

26. Magis D, D'Ostilio K, Thibaut A, et al. Cerebral metabolism before and after external trigeminal nerve stimulation in episodic migraine. Cephalalgia 2017;37:881-891.

27. Nagy AJ, Gandhi S, Bhola R, Goadsby PJ. Intravenous dihydroergotamine (DHE) for inpatient management of refractory primary headaches. Neurology 2011;77: $1827-1832$

28. Goadsby PJ, Edvinsson L. Human in vivo evidence for trigeminovascular activation in cluster headache. Brain 1994;117:427-434.

29. Vollesen ALH, Snoer A, Beske RP, et al. Effect of infusion of calcitonin gene-related peptide on cluster headache attacks: a randomized clinical trial. JAMA Neurol 2018; 75:1187-1197.

30. Karsan N, Bose P, Lowe JT, Goadsby PJ. The phenotype of premonitory symptoms and migraine headache triggered with nitroglycerin. J Neurol Neurosurg Psychiatry 2016;87:e1-e2.

31. Maniyar FH, Sprenger T, Monteith T, Schankin C, Goadsby PJ. Brain activations in the premonitory phase of nitroglycerin-triggered migraine attacks. Brain 2014;137: 232-241.

32. Schulte LH, May A. The migraine generator revisited: continuous scanning of the migraine cycle over 30 days and three spontaneous attacks. Brain 2016;139: 1987-1993.

33. Martins Oliveira M, Akerman S, Tavares I, Goadsby PJ. Neuropeptide Y inhibits the trigeminovascular pathway through NPY Y1 receptor: implications for migraine. Pain 2016;157:1666-1673.

34. Karsan N, Goadsby PJ. Biological insights from the premonitory symptoms of migraine. Nat Rev Neurol 2018;14:699-710.

35. Olesen J, Diener HC, Husstedt IW, et al. Calcitonin gene-related peptide recepto antagonist BIBN 4096 BS for the acute treatment of migraine. N Engl J Med 2004 350:1104-1110.

36. Ho TW, Ferrari MD, Dodick DW, et al. Efficacy and tolerability of MK-0974 (telcagepant), a new oral antagonist of calcitonin gene-related peptide receptor, com pared with zolmitriptan for acute migraine: a randomised, placebo-controlled, parallel-treatment trial. Lancet 2008:372:2115-2123.

37. Ho T, Mannix L, Fan X, et al. Randomized controlled trial of an oral CGRP antag onist, MK-0974, in acute treatment of migraine. Neurology 2008;70:1004-1012.

38. Connor KM, Shapiro RE, Diener HC, et al. Randomized, controlled trial of telcagepant for the acute treatment of migraine. Neurology 2009;73:970-977.

39. Marcus R, Goadsby PJ, Dodick D, Stock D, Manos G, Fischer T. BMS-927711 for the acute treatment of migraine: a double-blind, randomized, placebo-controlled, doseranging trial. Cephalalgia 2013;33(suppl 8):94.

40. Lipton RB, Coric V, Stock EG, et al. Rimegepant $75 \mathrm{mg}$, an oral calcitonin generelated peptide antagonist, for the acute treatment of migraine: two phase 3, doubleblind, randomized, placebo-controlled trials. Cephalalgia 2018;38(2S):18-19. 
41. Diener HC, Barbanti P, Dahlof C, Reuter U, Habeck J, Podhorna J. BI 44370 TA, an oral CGRP antagonist for the acute treatment of migraine attacks: results from a phase II study. Cephalalgia 2011;31:573-584.

42. Hewitt DJ, Aurora SK, Dodick DW, et al. Randomized controlled trial of the CGRP receptor antagonist, MK-3207, in the acute treatment of migraine. Cephalalgia 2011; 31:712-722.

43. Voss T, Lipton RB, Dodick DW, et al. A phase IIb randomized, double-blind, placebocontrolled trial of ubrogepant for the acute treatment of migraine. Cephalalgia 2016; 36:887-898.

44. Dodick DW, Lipton RB, Ailani J, et al. Ubrogepant for the acute treatment of migraine: efficacy, safety, tolerability, and functional impact outcomes from a single attack phase III study, ACHIEVE I. Headache 2018;58:1287-1288.

45. Lipton RB, Dodick DW, Ailani J, et al. Efficacy, safety, and tolerability of ubrogepant for the acute treatment of migraine: results from a single attack phase III study, ACHIEVE II. Headache 2018;58:1315-1316.

46. Saper J, Lipton R, Kudrow D, et al. A phase 3, randomized, double-blind, placebocontrolled study to evaluate the efficacy and safety of eptinezumab in frequent episodic migraine prevention: primary results of the PROMISE 1 (PRevention Of Migraine via Intravenous eptinezumab Safety and Efficacy 1) Trial. Cephalagia. 2017;37:337.

47. Dodick DW, Goadsby PJ, Spierings ELH, Scherer JC, Sweeney SP, Grayzel DS. CGRP monoclonal antibody LY2951742 for the prevention of migraine: a phase 2, randomized, double-blind, placebo-controlled study. Lancet Neurol 2014;13:885-892.

48. Skljarevski V, Matharu M, Millen BA, Ossipov MH, Kim BK, Yang JY. Efficacy and safety of galcanezumab for the prevention of episodic migraine: results of the EVOLVE-2 Phase 3 randomized controlled clinical trial. Cephalalgia 2018;38: 1442-1454.

49. Skljarevski V, Oakes TM, Zhang Q et al. Effect of different doses of galcanezumab vs placebo for episodic migraine prevention a randomized clinical trial. JAMA Neurol 2018;75:187-193.

50. Stauffer VL, Dodick DW, Zhang Q, Carter JN, Ailani J, Conley RR. Evaluation of galcanezumab for the prevention of episodic migraine: the EVOLVE-1 randomized clinical trial. JAMA Neurol 2018;75:1080-1088.

51. Aurora SK, Smith C, Brown RD, et al. Galcanezumab administration was not associated with increase in Blood Pressure in patients with osteoarthritis. Headache 2017; 57(suppl 3):136-137.

52. Bigal ME, Dodick DW, Rapoport AM, et al. Safety, tolerability, and efficacy of TEV48125 for preventive treatment of high-frequency episodic migraine: a multicentre, randomised, double-blind, placebo-controlled, phase $2 \mathrm{~b}$ study. Lancet Neurol 2015; 14:1081-1090.

53. Dodick DW, Silberstein SD, Bigal ME, et al. Effect of fremanezumab compared with placebo for prevention of episodic migraine: a randomized clinical trial. JAMA 2018; 319:1999-2008.

54. Bigal ME, Edvinsson L, Rapoport AM, et al. Safety, tolerability, and efficacy of TEV48125 for preventive treatment of chronic migraine: a multicentre, randomised, double-blind, placebo-controlled, phase 2b study. Lancet Neurol 2015;14: 1091-1100.

55. Dodick D, Goadsby P, Silberstein S, Lipton R, Hirman J, Smith J. Randomized, double-blind, placebo-controlled Trial of ALD403, an anti-CGRP peptide antibody in the prevention of chronic migraine. (S52.003). Neurology 2017;88(16 suppl).

56. Detke HC, Goadsby PJ, Wang S, Friedman DI, Selzler K, Aurora SK. Galcanezumab in chronic migraine: the randomized, double-blind, placebo-controlled REGAIN study. Neurology (Minneap) 2018;91:e2211-e221.

57. Smith JT, Dodick DW, Goadsby PJ, et al. Randomized, double-blind, placebocontrolled trial of ALD403, an anti-CGRP antibody in the prevention of chronic migraine. Headache 2016;56:1391.

58. Sun H, Dodick DW, Silberstein S, et al. A randomised, double-blind, placebocontrolled, phase 2 study to evaluate the efficacy and safety of AMG 334 for the prevention of episodic migraine. Lancet Neurol 2016;15:382-390.

59. Goadsby PJ, Reuter U, Hallström Y, et al. A controlled trial of erenumab for episodic migraine. N Engl J Med 2017;377:2123-2132.

60. Dodick DW, Ashina M, Brandes JL, et al. ARISE: a phase 3 randomized trial of erenumab for episodic migraine. Cephalalgia 2018;38:1026-1037.

61. Ashina M, Dodick D, Goadsby PJ, et al. Erenumab (AMG 334) in episodic migraine: interim analysis of an ongoing open-label study. Neurology 2017;89:1237-1243.

62. Reuter U, Goadsby PJ, Lanteri-Minet M, et al. Efficacy and tolerability of erenumab in episodic migraine patients who previously failed $2-4$ preventive treatments: a randomised placebo-controlled phase $3 \mathrm{~b}$ study. Lancet 2018;392:2280-2287.

63. Tepper SJ, Ashina M, Reuter U, et al. A phase 2, randomised, double-blind, placebocontrolled study to evaluate the efficacy and safety of erenumab in chronic migraine prevention. Lancet Neurol 2017;16:425-434.

64. Ho TW, Connor KM, Zhang Y, et al. Randomized controlled trial of the CGRP receptor antagonist telcagepant for migraine prevention. Neurology (Minneap) 2014; 83:958-966.
65. Goadsby PJ, Dodick DW, Trugman JM, et al. Efficacy, safety, and tolerability of orally administered atogepant for the prevention of episodic migraine: results from a phase 2b/3 study. Cephalalgia 2018;38:22-23.

66. Ferrari MD, Färkkilä M, Reuter U, et al. Acute treatment of migraine with the selective 5-HT1F receptor agonist lasmiditan: a randomised proof-of-concept trial. Cephalalgia 2010;30:1170-1178.

67. Farkkila M, Diener HC, Geraud G, et al. Efficacy and tolerability of lasmiditan, an oral 5-HT(1F) receptor agonist, for the acute treatment of migraine: a phase 2 randomised, placebo-controlled, parallel-group, dose-ranging study. Lancet Neurol 2012 11:405-413.

68. Kuca B, Silberstein SD, Wietecha L, et al. Lasmiditan is an effective acute treatment for migraine: a phase 3 randomized study. Neurology 2018;91:e2222-e2232.

69. Goadsby PJ, Wietecha LA, Dennehy EB, et al. Phase 3 randomized, placebocontrolled, double-blind study of lasmiditan for acute treatment of migraine. Brain (in press 2019).

70. Lipton RB, Dodick DW, Silberstein SD, et al. Single-pulse transcranial magnetic stimulation for acute treatment of migraine with aura: a randomised, double-blind, parallel-group, sham-controlled trial. Lancet Neurol 2010;9:373-380.

71. Bhola R, Kinsella E, Giffin N, et al. Single-pulse transcranial magnetic stimulation (sTMS) for the acute treatment of migraine: evaluation of outcome data for the UK post market pilot program. J Headache Pain 2015;16:51.

72. Starling AJ, Tepper SJ, Marmura MJ, et al. A multicenter, prospective, single arm, open label, observational study of sTMS for migraine prevention (ESPOUSE study). Cephalalgia 2018;38:1038-1048.

73. Saper J, Dodick DW, Silberstein S, McCarville S, Sun M, Goadsby PJ. Occipital nerve stimulation for the treatment of intractable chronic migraine headache: ONSTIM feasibility study. Cephalalgia 2011;41:271-285.

74. Silberstein S, Dodick D, Saper J, et al. The safety and efficacy of occipital nerve stimulation for the management of chronic migraine. Cephalalgia 2012;32: 1165-1179.

75. Lipton RB, Goadsby PJ, Cady RK, et al. PRISM study: occipital nerve stimulation for treatment-refractory migraine. Cephalalgia 2009;29(suppl 1):30.

76. Tassorelli C, Grazzi L, de Tommasi M, et al. Noninvasive vagus nerve stimulation as acute therapy for migraine the randomized PRESTO study. Neurology (Minneap) 2018;91:e364-e373.

77. Silberstein SD, Calhoun AH, Lipton RB, et al. Chronic migraine headache prevention with non-invasive vagus nerve stimulation: the EVENT study. Neurology (Minneap) 2016;87:529-538.

78. Chou DE, Shnayderman Yugrakh M, Winegarner D, Rowe V, Kuruvilla D, Schoenen J. Acute migraine therapy with external trigeminal neurostimulation (ACME) a randomized controlled trial. Cephalalgia 2018;39:3-14.

79. Schoenen J, Vandersmissen B, Jeangette S, et al. Migraine prevention with a supraorbital transcutaneous stimulator: a randomized controlled trial. Neurology 2013;80:697-704

80. Silberstein SD, Mechtler LL, Kudrow DB, et al. Non-invasive vagus nerve stimulation for the ACute treatment of cluster headache: findings from the randomized, doubleblind, sham-controlled ACT1 study. Headache 2016;56:1317-1332.

81. Goadsby PJ, de Coo IF, Silver N, et al. Non-invasive vagus nerve stimulation for the acute treatment of episodic and chronic cluster headache: a randomized, double-blind, sham-controlled ACT2 study. Cephalalgia 2018;38:959-969.

82. Gaul C, Diener HC, Silver N, et al. Non-invasive vagus nerve stimulation for PREVention and acute treatment of chronic cluster headache (PREVA): a randomised controlled study. Cephalalgia 2016;36:534-546.

83. Goadsby PJ, Dodick DW, Leone M, et al. Controlled trial of galcanezumab in the preventive treatment of episodic cluster headache. New Engl J Med (in press 2019).

84. Schoenen J, Jensen RH, Lanteri-Minet M, et al. Stimulation of the sphenopalatine ganglion (SPG) for cluster headache treatment-pathway $\mathrm{CH}-1$ : a randomized, sham controlled study. Cephalalgia 2013;33:816-830.

85. Goadsby PJ, Sahai-Srivastava S, Kezirian EJ, et al. Sham-controlled study of sphenopalatine ganglion stimulation for chronic cluster headache. Headache 2018;58: 1316-1317.

86. Barloese M, Petersen A, Stude P, Jürgens T, Jensen RH, May A. Sphenopalatine ganglion stimulation for cluster headache, results from a large, open-label European registry. J Headache Pain 2018;19:6.

87. Jurgens TP, Barloese M, May A, et al. Long-term effectiveness of sphenopalatine ganglion stimulation for cluster headache. Cephalalgia 2017;37:423-434.

88. Wilbrink LA, Teernstra OP, Haan J, et al. Occipital nerve stimulation in medically intractable, chronic cluster headache: the ICON study: rationale and protocol of a randomised trial. Cephalalgia 2013;33:1238-1247.

89. Fontaine D, Lazorthes Y, Mertens P, et al. Safety and efficacy of deep brain stimulation in refractory cluster headache: a randomized placebo-controlled double-blind trial followed by a 1-year open extension. J Headache Pain 2010;11:23-31.

90. Tso AR, Marin JCA, Goadsby PJ. Non-invasive vagus nerve stimulation for treatment of indomethacin-sensitive headaches. JAMA Neurol 2017;74:1266-1267. 


\title{
Neurology ${ }^{\circ}$ Clinical Practice
}

\author{
Primary headache disorders: Five new things \\ Peter J. Goadsby \\ Neurol Clin Pract 2019;9;233-240 Published Online before print May 17, 2019 \\ DOI 10.1212/CPJ.0000000000000654
}

This information is current as of May 17, 2019

\begin{abstract}
Updated Information \&
Services

including high resolution figures, can be found at:

http://cp.neurology.org/content/9/3/233.full.html

References

This article cites 87 articles, 7 of which you can access for free at: http://cp.neurology.org/content/9/3/233.full.html\#\#ref-list-1

Citations

This article has been cited by 4 HighWire-hosted articles:

http://cp.neurology.org/content/9/3/233.full.html\#\#otherarticles

Subspecialty Collections

This article, along with others on similar topics, appears in the following collection(s):

All Clinical trials

http://cp.neurology.org//cgi/collection/all_clinical_trials

All Headache

http://cp.neurology.org//cgi/collection/all_headache

Permissions \& Licensing

Information about reproducing this article in parts (figures,tables) or in its entirety can be found online at:

http://cp.neurology.org/misc/about.xhtml\#permissions

Reprints

Information about ordering reprints can be found online:

http://cp.neurology.org/misc/addir.xhtml\#reprintsus
\end{abstract}

Neurol Clin Pract is an official journal of the American Academy of Neurology. Published continuously since 2011, it is now a bimonthly with 6 issues per year. Copyright Copyright $\odot 2019$ The Author(s). Published by Wolters Kluwer Health, Inc. on behalf of the American Academy of Neurology.. All rights reserved. Print ISSN: 2163-0402. Online ISSN: 2163-0933.

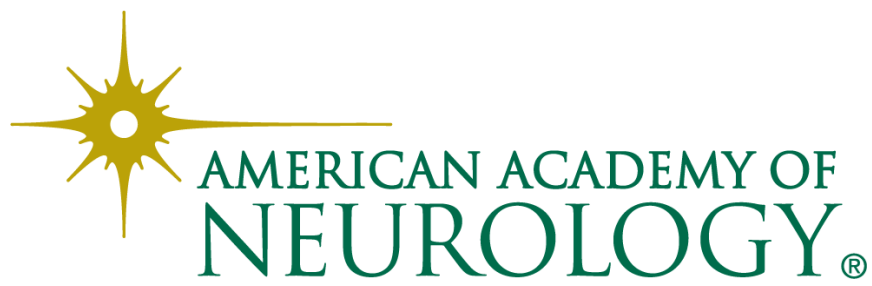

